\title{
Survey and Study on the Effects of New Media Technology on College Students
}

\author{
Mei Bie ${ }^{1, a}$, Zhe Wang ${ }^{2, ~ b}$, Jian Zhang ${ }^{3, c}$ \\ ${ }^{1}$ Institute of Media and Communications, Changchun Normal University, Jilin Province, P.R.China \\ ${ }^{2}$ Educational Technology Center of Jilin Province, Jilin Province, P.R.China \\ ${ }^{3}$ Center for Faculty Development, Northeast Normal University, Jilin Province, P.R.China \\ abie-mei@163.com, ${ }^{\mathrm{b}}$ Wangz721@hotmail.com, ${ }^{\mathrm{C}} 41131735 @ q q . c o m$
}

\begin{abstract}
Keywords: New Media Technology; Higher Education; College Students
Abstract. It shows that college students as a representative of the new media user has become an important part of Internet culture. The advantages of new media applications in the field of higher education are: achieve the mobile learning, change the interaction form between college teachers and students, and improve the college teaching mode. Although the college educators expect more of the new media could be used in learning, $32.3 \%$ of the percentage is inevitably cause a feeling of loss to some extent. College teachers obliged to carefully think about new media applications in higher education in order to broaden the horizons of college students learning, so that the new media technology could give college students more positive impact.
\end{abstract}

\section{Introduction}

Media no longer just influence our culture. They are our culture. [1]The new media has extended to every corner of our society. According to the 31st report of Chinese Internet Development Statistics Report which was released by Chinese Internet Network Information Center shows that as of June 2013, Chinese netizens reached 591 million [2], 18 to 29 year-olds accounted for $29.5 \%$ In the new media users, mostly college students, and the number of college students still increase continuously year by year, it shows that college students as a representative of the new media user has become an important part of Internet culture. Predictably, the influence of the new media, especially the impact on college students will be increasing.

Everything has two sides, the media is a double edged sword, on the one hand, it can bring knowledge and a tremendous amount of information to the students; on the other hand, it may spread some false and vulgar information to mislead students. Therefore, educators should gradually lead students to know and understand the new media, interpret the information correctly and improve students' ability to identify information, resist harmful media information consciously. [3]

\section{Advantages of New Media Applications to Higher Education}

In the 1960s, Marshall McLuhan noted that the majority of learning takes place outside the classroom today. Information through newspapers, magazines, movies, television and radio transmitted far more than the amount of information which was delivered by school teaching and textbooks. [4]The new media produced a lot of information anytime, anywhere, to attract more and more users to use, reproduce and distribute information which achieve information gather. The advantages of new media applications in the field of higher education are:

Achieve the mobile learning. Mobile learning is the use of wireless mobile communications network technology, apply wireless mobile communication devices (such as mobile phones, personal digital assistants PDA, Pocket PC, etc.) to obtain educational information, and realize a new form of digital learning educational resources and educational services.[5] Mobile learning is to make the learning happened anytime autonomous, which allows people to take advantage of the fragmented time, real-time access to information they need. User can quickly and easily using simple language to express their views, access and learn a technical knowledge of some disciplines, to reprint existing educational 
information and rethinking the ideas as the secondary outputs. The new media could publish information for at any time, and provide the technical support to build a virtual learning environment, mobile learning. [6]

Change the interaction form between college teachers and students. Improve the teacher-student relationship is an integral part of teaching. The new media technology enriches the form of teacher-student interaction, in addition to the traditional face-to-face teacher-student interaction method; the key-to-key interaction form has become a new trend. Through the Facebook, Blog, Microblogging, Wechat and other new media products, both college teachers and students could get a more comprehensive understanding of each other. In front of the students, not just on the dull image, but full of character----emotional, real, cute teacher; in front of teachers, it is no longer just a innocent child, but healthy, indulgent youth teenager. Meanwhile, compare with the face-to-face interaction form between teachers and students, the key-to-key method could release stress, help teachers and students to express true feelings. Teachers can truly observe individual students closely, which targeted implementation of teaching, guiding the personal development of students; students can also accept the guidance from teachers in a relaxed atmosphere, getting the life inspiration, which accumulated growth momentum. Therefore, the teachers should follow the basic principles of the new interactive media relations, such as being polite and respectful in the communication, and exchanging information under the premise of equality.

Improve the college teaching mode. The most significant impact on universities teaching of the new media technology is reflected in the innovative teaching mode, therefore the college educational practitioner should make full use of the unique advantages of the new media, just like fast, convenient, flexible, and lively. First, increase the number of the quality curriculum, develop more useful courseware and software with illustrations of modern educational technology and audio-visual effects. Second, to strengthen teacher-student interaction in the classroom teaching which is good for inspiring consciousness of students, the college teachers guide students to participate in teaching activities actively. Informative teaching, through new media technology, allows students to understand the knowledge in experiential education, acquire skills and understanding of the skills in a real work environment. The significance of the new media applications to higher education is promoting students to turn knowledge into skills. [7] The traditional teaching like the analytical formula and performing teaching combined with new media technology closely reflect the diversity and flexibility of the higher forms.

\section{The status quo of new media use of the college students}

In order to understand the situation how college students use the new media, we designed the questionnaire, and 200 college students of Changchun Normal University took apart in the investigation. 195 valid questionnaires were recovered, the effective rate is $97.5 \%$, and the survey data was analysis by statistical processing, the survey sample was shown as Fig $\mathbf{1 .}$

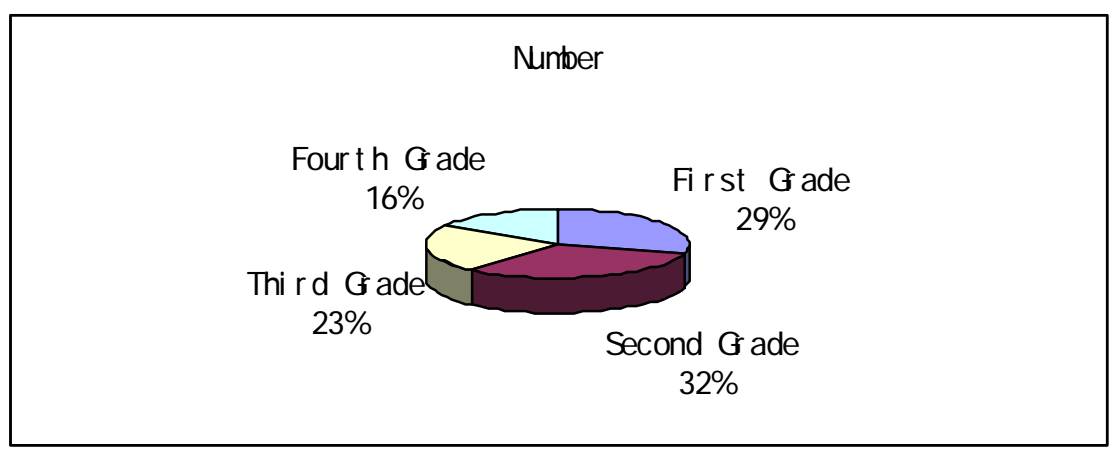

Fig 1. Survey sample of the research 
The first question is what kind of devices would you like to use? Because of the limitations of their own conditions, the survey data of this question indicated that college students access to the new media mainly in mobile phones, relatively, only a small number of students choose other types of devices. 77.4 percent of college students use computers, 95.9 percent of college students use mobile phones, 24.1 percent of college students use tablet computers, 13.3 percent of college students use other new media device, as shown in Fig 2.

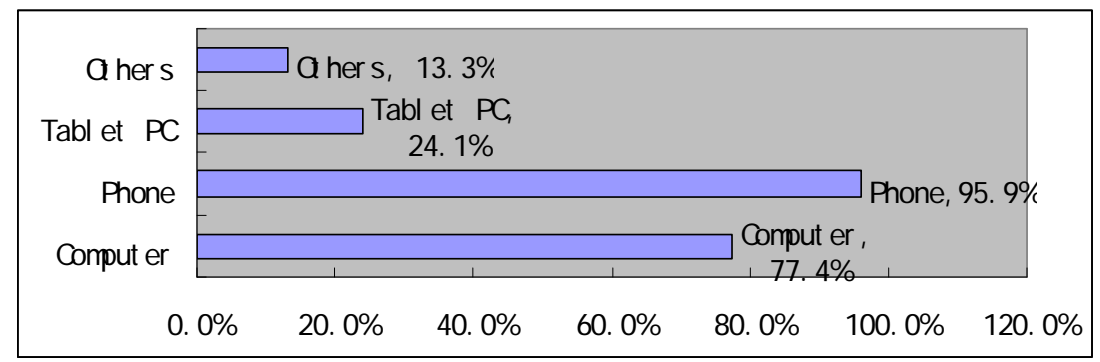

Fig 2. Answers of the question what kind of devices would you like to use

It is known through surveys and statistics that the main purpose of college students use new media as shown in Fig 3.: a) Learning, college students accounted for 32.3 percent of the growth of knowledge; b) Communication accounted for $42.1 \%$; c) Entertainment accounting for 54.9\%; d) Kill time accounted for $30.3 \%$; e) Others is $20.5 \%$.

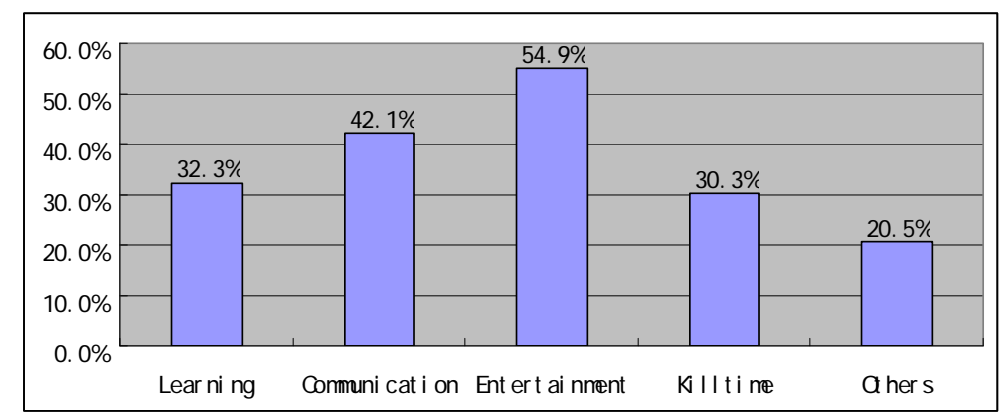

Fig 3. The purpose of college students use new media

New media technologies are increasingly affecting people's lives; especially for the college students those who would like accept the new things. They are using new media mostly and directly. The new media with its unique way affects the human society, especially the college students. It has changed the way of how college students learning and enrich the content of the undergraduate days of college students. Although the college educators expect more of the new media could be used in learning, $32.3 \%$ of the percentage is inevitably cause a feeling of loss to some extent. College teachers obliged to carefully think about new media applications in higher education in order to broaden the horizons of college students learning, so that the new media technology could give college students more positive impact.

\section{Guide students to rationalize the use of new media}

Try to build the interactive platform. The leaders of universities should focus on building new media platforms for theoretical study and the open discussions, spread advanced culture, and guide the objective and fair attitude. A dedicated teacher is responsible for answering various learning problems and puzzles from the students, trying to contribute a bridge of communication, and changing the indoctrination education to be permeate education. Make full use of mobile phones, Internet and other new media used by college students frequently, and take the advantages of the new media application 
to the lectures, model tests, and theme activities to help students resolve difficulties and problems encountered in their study.

Attaches great importance to new media literacy education of the college students. Media literacy education is to guide college students to correctly understand and use the mass media resources constructively, therefore the college students could be able to use the media resources to improve themselves and participate in social development with a critical thinking. [8]According to the survey data, college students using the new media are more a lack of rational understanding, identification and critical capability. The college educators could guide the college student participation in the learning activities or contest of the university, province or the country. Let the college student access to the new media through these activities; develop their ability to think independently, thereby gradually increasing their media literacy.

\section{Conclusion}

The impact of the new media technology to higher education has both desirable and undesirable characteristics. [9]College students should learn how to take the advantages of the new media to enrich their personal learning life, and improve their media literacy; at the same time, the college teachers should apply the new media technologies into their educational process, regardless of learning activities in the classroom, or out-of-school communication. In spite of many obstacles, the practitioners should devise creative ways to integrate new media into the learning process. [10]

\section{Acknowledgements}

This work was financially supported by Jilin Philosophy and Social Science Foundation (2015BS27), Jilin Educational Scientific Research Leading Group (GH14359), and Changchun Normal University under Contract No. [2011]009.

\section{References}

[1] E. Thoman, T. Jolls and Center for Media Literacy, in: Literacy for the $21^{\text {st }}$ Century (2008)

[2] Information on http://tech.163.com/special/cnnic32/

[3] C. H. Shi: submitted to Xi'An University of Science and Technology

[4] C. Liu, in: Software Guide. Vol.11(2011), p. 6-8

[5] Y. Liu, in: Educational Technology and Equipment in China. Vol.24(2012), p. 49-50

[6] L. Shi, in: Forestry Education in China. Vol.11(2013), p. 32-35

[7] H. B. Cong, in: Journal of Liaoning Educational Administration Institute.Vol.1 (2013), p. 69-71

[8] Z. Wang, in: Studies in Ideological Education. Vol.1 (2010), p. 74

[9] M. S. Yu, M. Li, and J. Hao, in: Journal of Social Science of Hunan Metrical University, Vol.11(2009), p. 78-79

[10] C. J. Pascoe, in: Theory Into Practice, Vol.51 (2012), p. 76-82 